\title{
Parametric design for quality improvement of injection-moulded product in a consumer electronics conglomerate
}

\author{
K.V.S. Rajeswara Rao* and V. Ravishankar \\ Department of Industrial Engineering and Management, \\ R V College of Engineering, \\ Mysore Road, Bengaluru 560059, Karnataka, India \\ Email: getkvs@gmail.com \\ Email: ravishankarv@rvce.edu.in \\ *Corresponding author
}

\begin{abstract}
Current global market trends place an enormous amount of pressure on the process engineers to deliver functional products at the lowest possible cost. Taguchi's robust design methods provide a systematic and efficient method for developing improved products at reduced cost. This paper presents an application of Taguchi's parametric design methodology which is popularly known as robust design methodology to achieve improvements in product quality through process optimisation in a manufacturing context undertaken at the automation division of one of India's largest consumer electronics conglomerate. Plastic-moulded components are manufactured using automatic injection moulding machines to meet the needs of the entire group. During the preliminary investigation it was observed that sink mark on the surface of the moulded plastic component was the main contributor for rejection of the components and hence was selected as a measure for quality improvement. Taguchi's methods were applied and significant improvements in quality levels followed leading to an improvement of $84.95 \%$ reduction in current rejection rates. The authors advocate the need for manufacturing organisations to adopt Taguchi's robust design methodologies for process optimisation so as to achieve higher levels of quality on a continuing basis to sustain the intense global competitive pressures.
\end{abstract}

Keywords: consumer electronics; control factors; injection moulded products; main and interaction effects; orthogonal array; quality improvement; robust design; sink marks; Taguchi and signal-to-noise ratio.

Reference to this paper should be made as follows: Rajeswara Rao, K.V.S. and Ravishankar, V. (2016) 'Parametric design for quality improvement of injection-moulded product in a consumer electronics conglomerate', Int. J. Experimental Design and Process Optimisation, Vol. 5, Nos. 1/2, pp.41-52.

Biographical notes: Dr Rajeswara Rao is an Associate Professor of Industrial Engineering and Management, R V College of Engineering, Bengaluru, India. $\mathrm{He}$ has been teaching and conducting research and provides consultancy services in the areas of Industrial Engineering, Ergonomics, Manufacturing Management and Human Resource Management. He received his Bachelors in Industrial and Production Engineering from R V College of Engineering, India, Masters in Manufacturing Management from BITS, Pilani, India and $\mathrm{PhD}$ in Business Administration with a specialisation in Human Resource Management from Kuvempu University, India. 
Ravishankar is currently an Assistant Professor in the Department of Industrial Engineering and Management in R V College of Engineering which is affiliated to the Visvesvaraya Technological University, India. He acquired his Bachelors in Mechanical Engineering along with Masters in Mathematics from Birla Institute of Technology and Science, Pilani, India. He worked for 12 years in a large telecom industry in turnkey projects of transportable telecommunication terminals involving mechanical design, product development, and integration. Subsequently he completed his Masters in Industrial and Systems Engineering from the Rutgers University, New Jersey. His areas of interest include Statistical Modelling and Energy Demand Management.

\section{Introduction}

Today's global competition demands the highest product quality and performance to be delivered at the shortest cycle time and the lowest unit cost. The emerging manufacturing paradigm necessitates an efficient development and delivery of robust product and process designs, differentiating the market leaders in a dynamic electronic component manufacturing sector. Currents trends in product offerings in terms of quality, cost, delivery and service include product quality at parts per million/parts per billion levels, delivery weeks and service $24 \mathrm{hrs} / 7$ days $/ 52$ weeks. These trends place an enormous amount of pressure on the process engineer to deliver a functional product at the lowest possible cost. Injection moulding is ideally suited for manufacturing large quantities of mass-produced plastic parts of complex shapes and sizes. Optimal setting of injection moulding process variables plays a very important role in controlling the quality of the injection moulded products (Mathivanan, Nouby and Vidhya, 2010). Applying and using design of experiments (DOEs) in injection moulding are relatively simple as compared to its use in other manufacturing or production processes, because most responses to process changes are linear (Kulkarni, 2010).

Sink mark is one of the most commonly found defects in injection-moulded components. Taguchi's approach is successfully applied in predicting sink depth for various combinations of processing variables (Mathivanan, Nouby and Vidhya, 2010). The influence of various parameters on the bending characteristic of the injectionmoulded plastic tray was experimented using Taguchi's philosophy (Kamaruddin et al., 2004). A full factorial design was used to study simultaneously the effect of five injection moulding process parameters namely backpressure, screw rotation speed, spear temperature, manifold temperature and holding pressure transfer influencing the short shot defect in a certain component for an air conditioner assembly (Yusoff et al., 2004). Optimum levels of injection moulding process parameters are determined by DOE technique of Taguchi and the analysis of variance (ANOVA) methods to minimise short shots (Rathi and Manoj, 2012). The process parameters are optimised using Taguchi and DOEs method to enhance the tensile and wear properties of injection-moulded polypropylene components (Lin et al., 2007). An orthogonal array as a tool is applied to optimise the moulding parameters such as injection pressure, injection temperature, powder loading, mould temperature, holding pressure and injection speed pressure and temperature to achieve highest green strength of components (Nor et al., 2011). Using statistical DOEs and predictive modelling it was found that barrel temperature and cycle 
time mostly affect the sink of the sprue for thermoplastic product manufactured by injection moulding process (Ghose et al., 2015). Literature thus establishes the fact that Taguchi's robust design methods are successfully deployed for industrial applications and they provide a systematic and efficient method for developing high quality products and processes at a low cost.

This paper presents an application of robust design methodology in a television manufacturing organisation to achieve improved quality levels through optimisation of process parameters and standardisation.

\section{Problem genesis}

The study was undertaken at an automation division of one of India's largest consumer electronics conglomerates. Plastic components are manufactured using automatic injection moulding machines. The major steps involved in the moulding process of the component selected are as follows:

- plasticisation of plastic raw material into homogeneous melts

- injection of the melt into the mould

- cooling of the mould

- ejection of the component.

The process has a large number of parameters to be set initially whose setting was based on experience and knowledge of the supervisor and was not systematically standardised. This led to defects like sink mark, air bubble, etc., and the total rejection rate amounted to $6.86 \%$. The Pareto diagram in the Figure 1 depicts the frequency of the occurrence of various defects in the manufacturing line. Forty seven percent of the rejections were due to sink mark and hence this defect was selected for detailed study. Robust design methodologies were applied in the above-mentioned context to demonstrate its potential for quality improvement.

Figure 1 Pareto diagram for rejections constituted by various defects (see online version for colours)

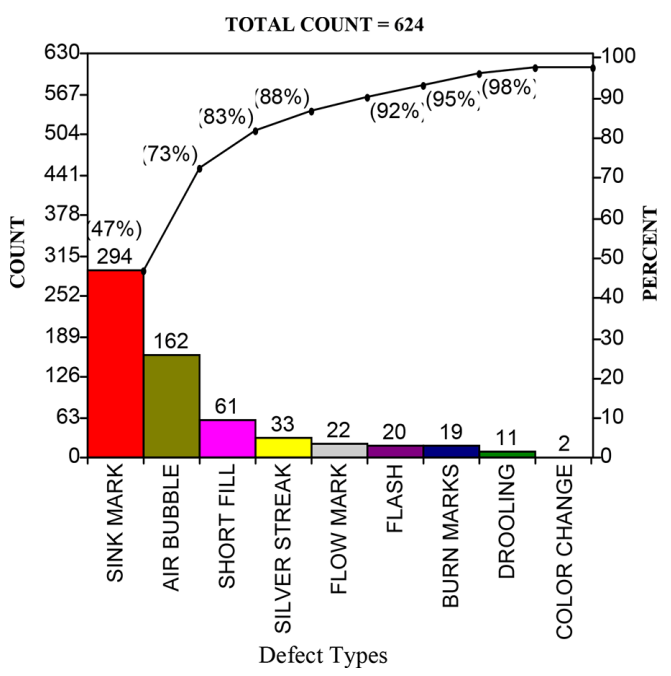




\section{Reduction of sink mark using robust design methodology}

Taguchi's robust design methodology using orthogonal array technique was used in bringing quality improvement in the moulded product by reducing the rejection rates due to sink mark. The following steps were deployed for experimentation and analysis.

\subsection{Problem definition and selection of quality characteristics}

The details pertaining to the product are selected for the study and its manufacturing process has been discussed in the problem genesis. It was also mentioned that the defect selected for study is sink mark as its occurrence was very high. The number of components rejected due to sink mark was appropriately selected as the quality characteristic.

\subsection{Selection of control (parameters) factors and their levels}

Injection moulding process typically has a large number of control parameters. The team consisting of the authors and the personnel at the industry had extensive brainstorming sessions to shortlist control parameters. For the problem of sink mark the parameters chosen and their levels are listed in Table 1 . In addition the interactions amongst certain parameters like $D \times F, E \times F$ and $E \times G$ were included in view of their suspected influence.

Table 1 Experimental control factors and levels

\begin{tabular}{lcc}
\hline Control parameters & Setting 1 & Setting 2 \\
\hline Gas pressure $(A$, bar $)$ & GPo & $\mathrm{GPo}+10$ \\
Gas timing $(B, \mathrm{~s})$ & $\mathrm{GTo}$ & $\mathrm{GTo}+2$ \\
Gas delay $(C, \mathrm{~s})$ & $\mathrm{GDo}$ & $\mathrm{GDo}+0.5$ \\
Barrel temperature $\left(D,{ }^{\circ} \mathrm{C}\right)$ & $\mathrm{BTo}$ & $\mathrm{BTo}+5$ \\
Cooling time $(E, \mathrm{~s})$ & $\mathrm{CTo}$ & $\mathrm{CTo}+2$ \\
Water temperature $\left(F,{ }^{\circ} \mathrm{C}\right)$ & $\mathrm{WTo}$ & $\mathrm{WTo}+2$ \\
Circulating water pressure $\left(G, \mathrm{kgf} / \mathrm{cm}^{2}\right)$ & $\mathrm{CPo}$ & $\mathrm{CPo}+1$ \\
Plasticising stroke $(H, \mathrm{~mm})$ & PSo & $\mathrm{PSo}+0.5$ \\
Back pressure $(I, \%)$ & $\mathrm{BPo}$ & $\mathrm{BPo}+10$ \\
\hline
\end{tabular}

\subsection{Matrix experiment design}

The standard orthogonal array selected for the case from tables is $\mathrm{L}_{16} 2^{15}$ (Phadke, M.S., 2008). The linear graphs are illustrated in Figure 2. The required linear graph for orthogonal array is represented in A. The standard linear graph from tables of orthogonal arrays is represented in $\mathrm{B}$. The $\mathrm{C}$ represents the modified linear graph with factors $\mathrm{A}$, $\mathrm{B}, \ldots, \mathrm{I}$ assigned to columns. The error indicates that the respective columns are not used for assignment. Based on this the experimental design matrix (Table 2) and experimenters log sheet (Table 3) comprising the randomisation of experiments were generated using DOE-PC IV software. 
Figure 2 Linear graphs (A) The required linear graph. (B) The standard linear graph from tables. (C) The modified linear graph

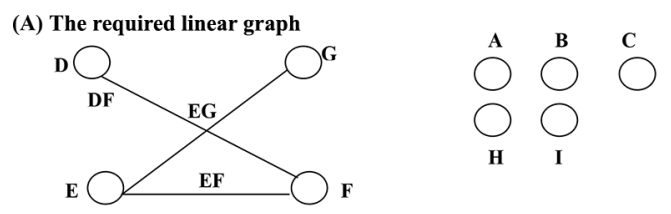

(B) The standard linear graph from tables
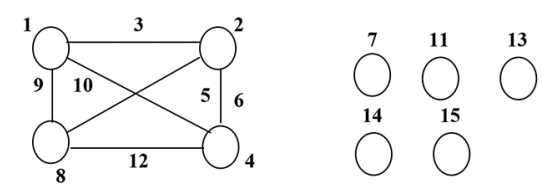

(C) The modified linear graph
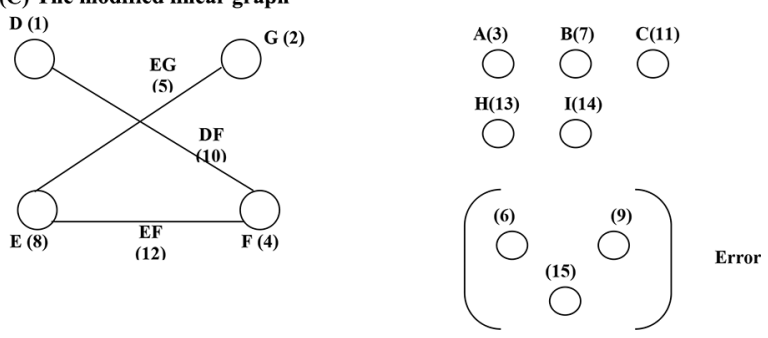

Table 2 Experimental design matrix

\begin{tabular}{llllllllll}
\hline & \multicolumn{7}{c}{ Experimental design matrix } \\
\cline { 2 - 9 } Experiment no. & $A$ & $B$ & $C$ & $D$ & $E$ & $F$ & $G$ & $H$ & $I$ \\
\hline 1 & 1 & 1 & 1 & 1 & 1 & 1 & 1 & 1 & 1 \\
2 & 1 & 1 & 2 & 1 & 2 & 1 & 1 & 2 & 2 \\
3 & 1 & 2 & 1 & 1 & 1 & 2 & 1 & 2 & 2 \\
4 & 1 & 2 & 2 & 1 & 2 & 2 & 1 & 1 & 1 \\
5 & 2 & 2 & 2 & 1 & 1 & 1 & 2 & 1 & 2 \\
6 & 2 & 2 & 1 & 1 & 2 & 1 & 2 & 2 & 1 \\
7 & 2 & 1 & 2 & 1 & 1 & 2 & 2 & 2 & 1 \\
8 & 2 & 1 & 1 & 1 & 2 & 2 & 2 & 1 & 2 \\
9 & 2 & 2 & 2 & 2 & 1 & 1 & 1 & 2 & 1 \\
10 & 2 & 2 & 1 & 2 & 2 & 1 & 1 & 1 & 2 \\
11 & 2 & 1 & 2 & 2 & 1 & 2 & 1 & 1 & 2 \\
12 & 2 & 1 & 1 & 2 & 2 & 2 & 1 & 2 & 1 \\
13 & 1 & 1 & 1 & 2 & 1 & 1 & 2 & 2 & 2 \\
14 & 1 & 1 & 2 & 2 & 2 & 1 & 2 & 1 & 1 \\
15 & 1 & 2 & 1 & 2 & 1 & 2 & 2 & 1 & 1 \\
16 & 1 & 2 & 2 & 2 & 2 & 2 & 2 & 2 & 2 \\
\hline
\end{tabular}


Table 3 Experimenter log sheet

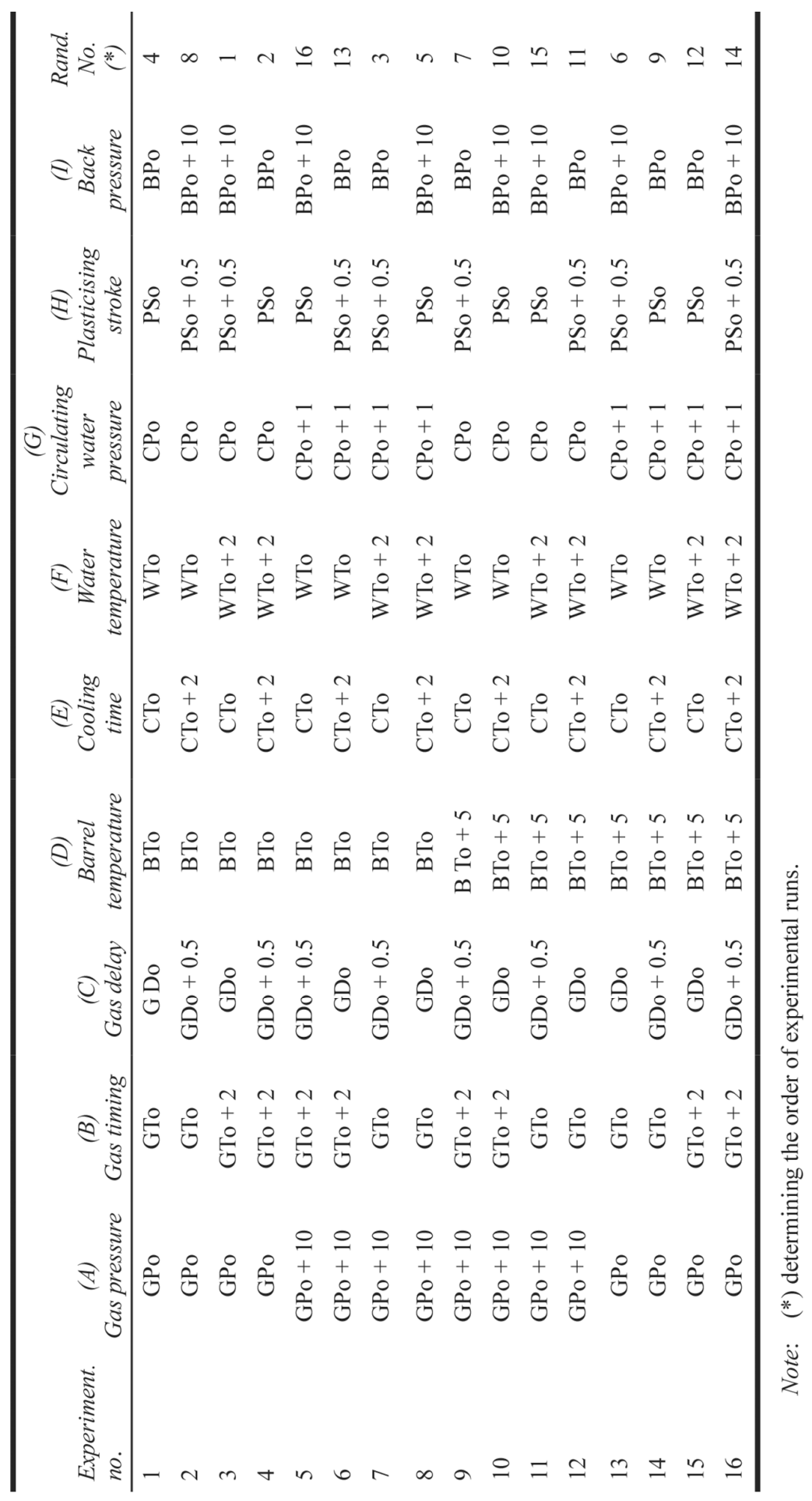




\subsection{Conducting the matrix experiment}

A total of 16 randomised experiments (Table 3) were conducted according to the experimenter's log. The experimentation was spread over three shifts with each experiment run having a sample of 100 components. The following Table 4 depicts the responses observed for each of the experiments. The response is the number of components rejected due to sink marks.

Table 4 Response values

\begin{tabular}{lcccccccccccccccc}
\hline Experiment no. & 1 & 2 & 3 & 4 & 5 & 6 & 7 & 8 & 9 & 10 & 11 & 12 & 13 & 14 & 15 & 16 \\
\hline Response $(y)$ & 1 & 4 & 2 & 3 & 0 & 0 & 2 & 2 & 3 & 1 & 1 & 1 & 1 & 1 & 0 & 0 \\
\hline
\end{tabular}

\subsection{Data analysis and interpretations}

According to the ANOVA analysis (Table 5) on number of rejections through DOE-PC $\mathrm{IV}$, the significant factors were found to be circulating water pressure $(G)$, barrel temperature $(D)$ and gas delay $(C)$. Based on the literature review, it was observed that an analysis with signal-to-noise ratio will provide better results as compared to analysis based purely on responses and number of defective components. Moreover, the software tool used for analysis does not provide factor effect and interaction effect plots, which are extremely important for analysis as they provide the graphical indication of the effects. Also the number of experimental runs involved is manageable for analysis. Hence, further analysis is conducted manually. Adopting the quadratic loss function for the fraction-defective type of the static problem, the objective function for the characteristic can be stated as follows:

$$
\text { Maximise } \eta=-10 \log _{10}\left[\frac{p}{1-p}\right]
$$

where $p$ is fraction defective and $\eta$ is signal-to-noise ratio.

As a first step in the analysis the signal-to-noise ratio values were calculated along with fraction defectives and listed in Table 6. Factor effects and interaction effects were plotted and are depicted in Figure 3.

Table 5 ANOVA output from DOE-PC IV software

\begin{tabular}{|c|c|c|c|c|c|}
\hline \multicolumn{6}{|c|}{ Analysis of sink marks on cabinets } \\
\hline \multicolumn{6}{|c|}{ ANOVA summary: based on the model specified by the interaction list } \\
\hline Level of model & $\begin{array}{c}\text { Sum of } \\
\text { squares } \\
\text { (partial SS) }\end{array}$ & $d f$ & Mean square & F ratio & Significance \\
\hline $\begin{array}{l}\text { Main } \\
\text { factors - linear }\end{array}$ & 13.250 & 9 & 1.472 & 1.039 & 0.500 \\
\hline Error & 8.500 & 6 & 1.417 & & \\
\hline Total & 21.750 & 15 & Undefined & & \\
\hline
\end{tabular}


Table 5 ANOVA output from DOE-PC IV software (continued)

\begin{tabular}{lcccc}
\hline \multicolumn{5}{c}{ ANOVA sources of variation: based on the model specified by the interaction list } \\
Sum of & $\begin{array}{l}\text { Surce } \\
\text { squares }\end{array}$ & $d f$ & F ratio & Significance \\
\hline Gas pressure $(A)$ & 0.250 & 1 & 0.176 & Undefined \\
Gas timing $(B)$ & 1.000 & 1 & 0.706 & Undefined \\
Gas delay $(C)$ & 2.250 & 1 & 1.588 & 0.746 \\
Barrel temperature $(D)$ & 2.250 & 1 & 1.588 & 0.746 \\
Cooling time $(E)$ & 0.250 & 1 & 0.176 & Undefined \\
Water temperature $(F)$ & 0.000 & 1 & 0.000 & Undefined \\
Circulating water $(G)$ & 6.250 & 1 & 4.412 & 0.921 \\
Plasticisings $(H)$ & 1.000 & 1 & 0.706 & Undefined \\
Back pressure $(I)$ & 0.000 & 1 & 0.000 & Undefined \\
\hline
\end{tabular}

Table 6 Signal-to-noise ratio analysis

\begin{tabular}{lcccccccccccccccc}
\hline $\begin{array}{l}\text { Experiment } \\
\text { no. }\end{array}$ & 1 & 2 & 3 & 4 & 5 & 6 & 7 & 8 & 9 & 10 & 11 & 12 & 13 & 14 & 15 & 16 \\
\hline$y$ & 1 & 4 & 2 & 3 & 0 & 0 & 2 & 2 & 3 & 1 & 1 & 1 & 1 & 1 & 0 & 0 \\
$p$ & 0.01 & 0.04 & 0.02 & 0.03 & 0 & 0 & 0.02 & 0.02 & 0.03 & 0.01 & 0.01 & 0.01 & 0.01 & 0.01 & 0 & 0 \\
$\eta$ & 19.9 & 13.8 & 16.9 & 15.09 & $-\infty$ & $-\infty$ & 16.9 & 16.9 & 15.09 & 19.9 & 19.9 & 19.9 & 19.9 & 19.9 & $-\infty$ & $-\infty$ \\
\hline
\end{tabular}

Figure 3 Plots of factor effects and interaction effects (see online version for colours)

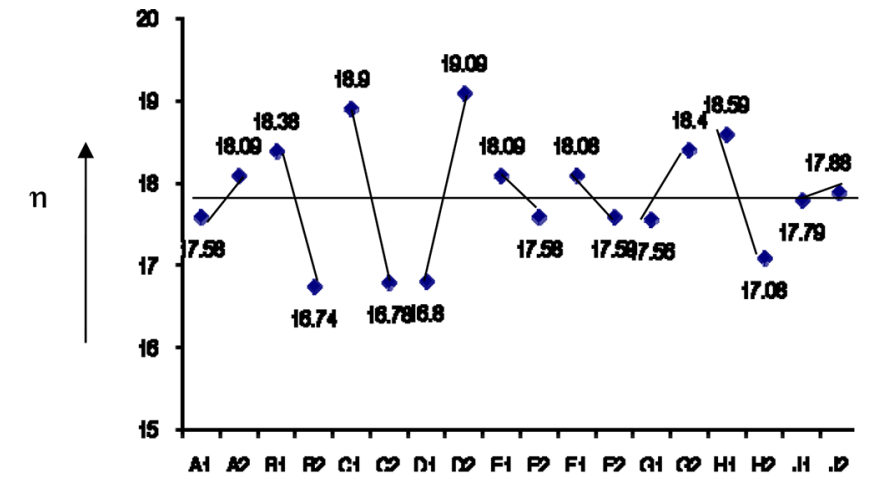

Overall mean $m=17.84 \mathrm{~dB}$
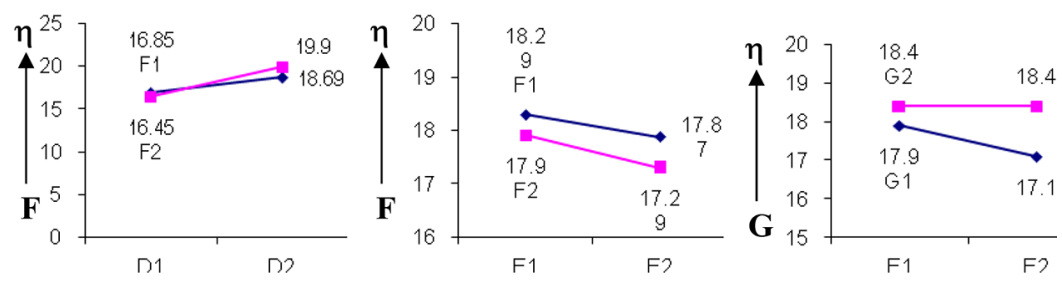

Following preliminary observations were made based on the plot of factor effects:

- $\quad$ Barrel temperature $(D)$ has the largest effect on the signal-to-noise ratio and the level of setting 2 is favourable. 
- $\quad$ Gas timing $(B)$, gas delay $(C)$ and plasticising stroke $(H)$ have the next largest effect and for these parameters, existing levels are favourable.

- $\quad$ Gas pressure $(A)$, cooling time $(E)$, water temperature $(F)$ and circulating water pressure $(G)$ have moderate effect.

- $\quad$ Back pressure $(I)$ has negligible effect.

A study of the plot of interaction effects provides the following inferences:

- $\quad$ Barrel temperature $(D)$ and water temperature $(F)$ interact mildly and do not affect the signal-to-noise ratio.

- Cooling time $(E)$ and water temperature $(F)$ do not interact significantly.

- Cooling time $(E)$ and circulating water pressure $(G)$ do not interact significantly.

The preliminary observations can be substantiated by carrying out ANOVA. Table 7 gives the ANOVA details. The calculated $F$ values for gas timing, gas delay, barrel temperature and plasticising stroke are greater than 4 , hence the factor effects on the signal-to-noise ratio are quite large. The effects of other factors are very minimal and hence negligible. The interaction of barrel temperature and water temperature has a moderate effect. The other interactions play an insignificant role. The summary of factor effects and variance ratios is listed in Table 7. For each factor, level-wise signal-to-noise ratio along with variance ratio for each factor is determined in Table 8 . The desirable settings are marked with an asterisk.

Thus, the optimum conditions for parameter setting recommended for implementation are $A_{2}, B_{1}, C_{1}, D_{2}, E_{1}, F_{1}, G_{2}, H_{1}$ and $I_{2}$ and listed in Table 9.

Table 7 Factor effects on signal-to-noise ratio

\begin{tabular}{|c|c|c|c|c|c|c|}
\hline \multirow[b]{2}{*}{ Factor } & \multicolumn{2}{|c|}{ Levels } & \multirow[b]{2}{*}{$\begin{array}{l}\text { Degrees } \\
\text { of freedom }\end{array}$} & \multirow[b]{2}{*}{$\begin{array}{l}\text { Sum of } \\
\text { squares }\end{array}$} & \multirow[b]{2}{*}{$\begin{array}{c}\text { Mean } \\
\text { squares }\end{array}$} & \multirow[b]{2}{*}{$\begin{array}{l}\text { Variance } \\
\text { ratio }(F)\end{array}$} \\
\hline & 1 & 2 & & & & \\
\hline Gas pressure $(A)$ & GPo Bar & $\mathrm{GPo}+10$ & 1 & 0.78 & 0.78 & 0.56 \\
\hline Gas timing $(B)$ & GTo Sec & $\mathrm{GTo}+2$ & 1 & 7.54 & 7.54 & 5.39 \\
\hline Gas delay $(C)$ & GDo Sec & $\mathrm{GDo}+0.5$ & 1 & 13.48 & 13.48 & 9.63 \\
\hline Barrel temperature $(D)$ & $\mathrm{BTo}^{\circ} \mathrm{C}$ & $\mathrm{BTo}+5$ & 1 & 18.90 & 18.90 & 13.5 \\
\hline Cooling time $(E)$ & CTo Sec & $\mathrm{CTo}+2$ & 1 & 0.78 & 0.78 & 0.56 \\
\hline Water temperature $(F)$ & $\mathrm{WTo}^{\circ} \mathrm{C}$ & WTo + 2 & 1 & 0.72 & 0.72 & 0.51 \\
\hline $\begin{array}{l}\text { Circulating water } \\
\text { pressure }(G)\end{array}$ & $\underset{\mathrm{kgf} / \mathrm{cm}^{2}}{\mathrm{CPo}}$ & $\mathrm{CPo}+1$ & 1 & 1.88 & 1.88 & 1.34 \\
\hline Plasticising stroke $(H)$ & PSo mm & PSo +0.5 & 1 & 6.84 & 6.84 & 4.89 \\
\hline Back pressure $(I)$ & ВРо \% & $\mathrm{BPo}+10$ & 1 & 0.02 & 0.02 & 0.01 \\
\hline$D \times F$ & & & 1 & 3.95 & 0.03 & 2.82 \\
\hline$E \times F$ & & & 1 & 0.03 & 0.45 & 0.02 \\
\hline$E \times G$ & & & 1 & 0.45 & 1.40 & 0.32 \\
\hline Error & & & 3 & 4.19 & & \\
\hline Total & & & 15 & 59.56 & & \\
\hline
\end{tabular}


Table 8 Factor levels and signal-to-noise ratio

\begin{tabular}{|c|c|c|c|}
\hline Factor & Level & $\eta(d B)$ & $F$ \\
\hline \multirow[t]{2}{*}{ Gas pressure $(A$, bar $)$} & GPo & 17.58 & \multirow{2}{*}{0.56} \\
\hline & $\mathrm{GPo}+10^{*}$ & 18.09 & \\
\hline \multirow[t]{2}{*}{ Gas timing $(B, \mathrm{~s})$} & GTo* & 18.38 & \multirow{2}{*}{5.39} \\
\hline & $\mathrm{GTo}+2$ & 16.74 & \\
\hline \multirow[t]{2}{*}{ Gas delay $(C, \mathrm{~s})$} & GDo* & 18.9 & \multirow{2}{*}{9.63} \\
\hline & $\mathrm{GDo}+0.5$ & 16.78 & \\
\hline \multirow[t]{2}{*}{ Barrel temperature $\left(D,{ }^{\circ} \mathrm{C}\right)$} & BTo & 16.58 & \multirow{2}{*}{13.5} \\
\hline & $\mathrm{BTo}+5^{*}$ & 19.09 & \\
\hline \multirow[t]{2}{*}{ Cooling time $(E, \mathrm{~s})$} & CTo* & 18.09 & \multirow{2}{*}{0.56} \\
\hline & $\mathrm{CTo}+2$ & 17.58 & \\
\hline \multirow[t]{2}{*}{ Water temperature $\left(F,{ }^{\circ} \mathrm{C}\right)$} & WTo* & 18.08 & \multirow{2}{*}{0.51} \\
\hline & $\mathrm{WTo}+2$ & 17.59 & \\
\hline \multirow[t]{2}{*}{ Circulating water pressure $\left(G, \mathrm{kgf} / \mathrm{cm}^{2}\right)$} & $\mathrm{CPo}$ & 17.56 & \multirow{2}{*}{1.34} \\
\hline & $\mathrm{CPo}+1^{*}$ & 18.4 & \\
\hline \multirow[t]{2}{*}{ Plasticising stroke $(H, \mathrm{~mm})$} & PSo* & 18.59 & \multirow{2}{*}{4.89} \\
\hline & PSo +0.5 & 17.08 & \\
\hline \multirow[t]{2}{*}{ Back pressure $(I, \%)$} & BPo & 17.79 & \multirow{2}{*}{0.01} \\
\hline & $\mathrm{BPo}+10^{*}$ & 17.88 & \\
\hline
\end{tabular}

Table 9 Recommended control factors and levels

\begin{tabular}{lcc}
\hline Control parameters & Existing level & Recommended level \\
\hline Gas pressure $(A$, bar $)$ & GPo & GPo +10 \\
Gas timing $(B, \mathrm{~s})$ & GTo & GTo \\
Gas delay $(C, \mathrm{~s})$ & GDo & GDo \\
Barrel temperature $\left(D,{ }^{\circ} \mathrm{C}\right)$ & BTo & BTo +5 \\
Cooling time $(E, \mathrm{~s})$ & CTo & CTo \\
Water temperature $\left(F,{ }^{\circ} \mathrm{C}\right)$ & WTo & WTo \\
Circulating water pressure & CPo & CPo +1 \\
$\left(G\right.$, kgf $\left./ \mathrm{cm}^{2}\right)$ & & \\
Plasticising stroke $(H, \mathrm{~mm})$ & PSo & PSo \\
Back pressure $(\mathrm{I}, \%)$ & BPo & BPo +10 \\
\hline
\end{tabular}




\subsection{Prediction}

The next step in data analysis is prediction of signal-to-noise ratio under optimum conditions.

$$
\begin{aligned}
\boldsymbol{\eta}_{\text {opt }} & =m+\left(B_{1}-m\right)+\left(C_{1}-m\right)+\left(D_{2}-m\right)+\left(H_{1}-m\right) \\
& =17.84+(18.38-17.84)+(18.9-1784)+(19.09-17.84)+(18.59-17.84)=\mathbf{2 1 . 4 4} \mathbf{d B} .
\end{aligned}
$$

Fraction defective under optimum conditions is computed as follows:

$$
\eta_{\mathrm{opt}}=-10 \log _{10}\left[\frac{p}{1-p}\right] \Rightarrow \frac{p}{1-p}=10^{-\frac{\eta_{\mathrm{opt}}}{10}}=10^{-\frac{20.69}{10}} \Rightarrow \boldsymbol{p}=\mathbf{0 . 0 0 7 1 3}
$$

Therefore, predicted fraction defective at the optimal parameter setting is $0.71 \%$.

\subsection{Verification}

Five experiments were conducted under optimum conditions and the percentage of rejection was found to be $1.03 \%$ which differs from predicted value by $0.32 \%$. But the rejection observed is substantially lower than existing $6.86 \%$ level thereby leading to an improvement of $85 \%$ reduction in rejection rate.

\section{Scope for further analysis}

The authors recommended the following future plan of action:

- Using the learning from the matrix experiment, several subsequent matrix experiments are to be conducted for achieving even finer improvements.

- Factor levels have to be taken sufficiently far apart so that a wide region can be covered.

- Consideration of three levels or usage of central composite designs for factors may help in identifying non-linear curvature effects.

\section{Conclusion}

The aforementioned case is a testimony to the fact that Taguchi's methods when applied for process optimisation result in significant quality improvements. The method has potentiality to generate quality improvements in various manufacturing processes, irrespective of the technological complexity. The authors opine that the manufacturing organisations should adopt Taguchi's robust design methodologies for process optimisation so as to achieve targeted quality levels on a continuing basis to sustain the intense global competitive pressures. This will not only enable the organisations to maintain the existing market share if not increase their share but also increase profitability by reducing the costs. 


\section{Acknowledgement}

The authors acknowledge the students, faculty and staff members involved in assisting the authors to conduct the experimentation, analysis and documentation.

\section{References}

Ghose, A., Montero, M. and Odell, D. (2015) 'Characterization of an injection molding process for improved part quality', www.urbookdownload.com, Accessed on 11-18-2015.

Kamaruddin, S., Khan, Z.A. and Wan, K.S. (2004) 'The use of Taguchi method in determining the optimum plastic injection moulding parameters for the production of a consumer product', Journal Mekanikal, Vol. 18, pp.98-110.

Kulkarni, S. (2010) Robust Process Development and Scientific Molding-Theory and Practice, Hanser Publications, Munich, Cincinnati, pp.145-167. ISBN:978-1-56990-501-2.

Lin, Y. H., Deng, W-J., Huang, C-H. and Yang, Y-K. (2007) 'Optimization of injection molding process for tensile and wear properties of polypropylene components via Taguchi and design of experiments method', Polymer-Plastics Technology and Engineering, Vol. 47, No. 1, pp.96-105.

Mathivanan, D., Nouby, M. and Vidhya, R. (2010) 'Minimization of sink mark defects in injection moulding process-Taguchi approach', International Journal of Engineering, Science and Technology, Vol. 2, No. 2, pp.13-22.

Nor, N. H. M., Muhamad, N., Ibrahim, M.H.I., Ruzi.M. and Jamaludin, K.R. (2011) 'Optimization of injection molding parameters of Ti-6Al-4V powder mix with palm stearin and polyethylene for the highest green strength by using Taguchi method', International Journal of Mechanical and Materials Engineering, Vol. 6, No. 1, pp.126-132.

Phadke, M. S. (2008) Quality Engineering Using Robust Design, Dorling Kindersley (India) Pvt. Ltd., Delhi, India. ISBN:978-81-317-2239-8.

Rathi, M.G. and Manoj, D.S. (2012) 'Analysis of injection molding process parameters', International Journal of Engineering Research and Technology, Vol. 1, No. 8, pp.1-5.

Taguchi, G. (1987) System of Experimental Design, Vol.1 and 2, in Don Clausing (Ed.), UNIPUB/Kraus International Publications, New York.

Yusoff, S.M.M., Rohani, J.M., Hamid, W.H.W. and Ramly, E. (2004) 'A plastic injection molding process characterization using experimental design technique: a case study', Journal Technologi, Vol. 41(A), pp.1-16. 